\title{
Square Micrometer
}

National Cancer Institute

\section{Source}

National Cancer Institute. Square Micrometer. NCI Thesaurus. Code C73770.

A SI unit of area measurement equal to a square whose sides are one micrometer long. 